\title{
Hypolithic and soil microbial community assembly along an aridity gradient in the Namib Desert
}

Francesca Stomeo, Angel Valverde, Stephen B. Pointing, Christopher P. McKay, Kimberley A. Warren-Rhodes, Marla I. Tuffin, Mary Seely and Don A. Cowan

\begin{abstract}
The Namib Dessert is considered the oldest desert in the world and hyperarid for the last 5 million years. However, the environmental buffering provided by quartz and other translucent rocks supports extensive hypolithic microbial communities. In this study, open soil and hypolithic microbial communities have been investigated along an East-West transect characterized by an inverse fog-rainfall gradient. Multivariate analysis showed that structurally different microbial communities occur in soil and in hypolithic zones. Using variation partitioning, we found that hypolithic communities exhibited a fog-related distribution as indicated by the significant East- West clustering. Sodium content was also an important environmental factor affecting the composition of both soil and hypolithic microbial communities. Finally, although null models for patterns in microbial communities were not supported by experimental data, the amount of unexplained variation (68-97 \%) suggests that stochastic processes also play a role in the assembly of such communities in the Namib Desert.
\end{abstract}

\section{Introduction}

With an estimated age of 80 million years, the Namib Desert, located in the southwest of the African continent, is believed to be the oldest dryland region in the world (Prestel et al. 2008). Although hyper-aridity, high winds, extreme temperatures and low nutrient availability all impose constraints on microbial life, microbial communities proliferate in these environments in "refuge" niches (Pointing and Belnap 2012; Chan et al. 2012). One of the most studied of these habitats is the lithic environment, where microbial communities have colonized the underside (hypolithic) or interior (endolithic) of translucent rocks.

Such communities are very widespread, but dominate standing biomass in the driest (Warren-Rhodes et al. 2006; 2007; Walker and Pace 2007; Azua-Bustos et al. 2011) and coldest (de la Torre et al. 2003; Pointing et al. 2009; Cary et al. 2010) deserts on Earth. Translucent rocks create microclimatic conditions where hypolithic microorganisms benefit from greater physical stability, desiccation buffering, increased water availability and protection from UV fluxes (Pointing et al. 2009; Cowan et al. 2010; Wong et al. 2010). 
Hypolithic communities in extreme desert environments may be the dominant sites of primary productivity (Tracy et al. 2010), contributing significantly to $\mathrm{N}$ input and carbon in the form of biomass (Cockell and Stokes 2004; Cowan et al. 2011). Hypoliths have been proposed as viable model systems for understanding the mechanisms underlying the assembly of bacterial communities (Caruso et al. 2011), a major goal in microbial ecology.

All studies on hypoliths have indicated that these communities are most commonly dominated by photosynthetic cyanobacteria, with a taxonomically diverse heterotrophic component dominated by the phyla Acidobacteria, Actino-bacteria, Bacteroidetes and Proteobacteria (Schlesinger et al. 2003; Warren-Rhodes et al. 2006, 2007; Pointing et al. 2007, 2009; Wood et al. 2008; Chan et al. 2012). However, the processes shaping the assembly of such communities are still poorly understood. Historically, community ecologists have focused on environmental conditions and interspecific interactions (deterministic factors) to explain how species diversity and composition vary along environmental and/or spatiotemporal gradients (Chase 2007). More recently, "neutral" theory (Hubbell 2001) has suggested that many natural patterns can be recreated only by considering stochastic assembly processes like birth, death, colonization, extinction and speciation. It is now widely accepted that community assembly can be either regulated by (1) purely deterministic processes, where habitat heterogeneity creates different niches in which different groups of species are favored; (2) purely stochastic processes; or (3) the interaction between stochastic and deterministic processes (Chase 2010; Ofiteru et al. 2010).

Understanding the mechanisms that regulate microbial community assembly is of special interest, because such mechanisms sustain biodiversity and ecosystem functioning. This is of particular relevance in arid systems, which are highly susceptible to disturbance, and may be particularly threatened by accelerated rates of climate change (Seager et al. 2007). Recently, it has been demonstrated that on a global scale stochastic and deterministic processes interact in structuring desert microbial communities (Caruso et al. 2011). In this instance, whilst heterotrophic assemblages could be explained partially by climatic and environmental variables, phototrophic bacterial assemblages exhibited strong signals related to demographic stochasticity. The latter has been attributed to the lack of gene flow among cyanobacteria in hypolithic systems (Bahl et al. 2011). Under harsh environmental conditions (such as those present in desert ecosystems), species sorting is thought to result in more deterministic communities (Chase 2007, 2010).

Water is a scarce resource in the Namib Desert. The annual mean rainfall at Gobabeb, in the central Namib Desert, recorded from 1962 to 2010, was $25 \mathrm{~mm}$ (Eckardt et al. 2012) occurring as sporadic events. Precipitation, therefore, is not a reliable source of water for sustaining life in the central arid region of this desert. Relative humidity and dew are important sources (Henschel and Seely 2008), but fog events, which are common in a zone from the coast to approx. $60 \mathrm{~km}$ inland (Eckardt et al. 2012), are thought to be the dominant source of bioavailable water in the region (Büdel et al. 2009). Water availability is considered to be one of the most important factors affecting hypolithic 
microbial populations in many terrestrial environments (Warren-Rhodes et al. 2006; Pointing et al. 2007; Azua-Bustos et al. 2011; Cary et al. 2010; Pointing and Belnap 2012). Both available liquid water, derived from rainfall (Warren-Rhodes et al. 2006; Pointing et al. 2007) and fog (Azua-Bustos et al. 2011), have been shown to be key determinants of hypolithic communities in hyper-arid regions. However, to our knowledge, the influence of water regime (in terms of fog and rainfall sources) in shaping the structure of desert microbial communities on a local scale has never been investigated.

Here, we assessed the relative importance of abiotic factors, such as water regime and soil chemical properties in explaining microbial community composition on a local scale. Specifically, we hypothesized that water regime (i.e. fog-vs. rainfall-dominated) is a driver of local-scale variation in microbial community composition. We have examined the structure of general (open soil) and specific (hypolithic) microbial communities through an EastWest transect across the Namib Desert. This transect has a well-established water availability gradient determined by fog and rainfall (Eckardt et al. 2012). We compared the metacommunity structure of hypolithons to those in adjacent open soil at each site, by means of variation partitioning and null model analysis, in an attempt to unravel the processes that govern their assembly.

\section{Materials and methods}

Sample collection and physicochemical analysis Samples were collected in April 2010 at ten sites along a V-shaped (northwest-southwest-northeast) transect that extended $100 \mathrm{~km}$ inland from Walvis Bay (Fig. 1). At each GPS-logged site, 5 independent hypolithic community samples were pooled into sterile Whirl-Pack sample bags (Nasco, WI, USA). All rocks were similar in composition (quartz), size $(12-15 \mathrm{~cm})$ and thickness $\left(5^{-7} \mathrm{~cm}\right)$ to minimize the influence of these factors in shaping the structure of microbial communities. Simultaneously, multiple open soil samples (0-5 $\mathrm{cm}$ in depth) were pooled, homogenized, and directly transferred into sterile $50 \mathrm{ml}$ tubes. Samples were stored at $4{ }^{\circ} \mathrm{C}$ after sampling and during transport to the laboratory, and then stored at $-80{ }^{\circ} \mathrm{C}$ until further analysis.

Total carbon, nitrogen, $\mathrm{pH}$, water content, potassium, calcium, sodium and magnesium were measured for each soil sample at BemLab (SANAS Accredited Testing Laboratory, Somerset West, South Africa), according to standard quality control procedures (SSSA 1996).

For clarification (see Fig. 1), western samples (G3, G9, G12, G15 and G18) are referred to collectively as fog-dominated, while eastern samples (G20, G22, G2, G27 and G29) are referred to as rainfall-dominated, following the climatic zonation of the Namib Desert (Eckardt et al. 2012).

\section{DNA extraction, PCR amplification and T-RFLP analysis}

Metagenomic DNA was extracted from triplicate sub-samples using the PowerSoil DNA Isolation Kit (MoBio, West Carlsbad, CA, USA) following the manufacturer's instructions. 
PCR amplification was performed with primer sets E9F (Hansen et al. 1998): $5^{\mathrm{O}_{-}}$ GAGTTTGATCCTG GCTCAG-3 ${ }^{O}$ and U1510R (Reysenbach and Pace 1995): $5^{\mathrm{O}_{-}}$ GGTTACCTTGTTACGACTT- $3^{\mathrm{O}}$, for bacteria; and $27 \mathrm{~F} 1$ (Jungblut et al. 2005): $5^{\mathrm{O}_{-}}$ AGAGTTTGATCCTGGCT-CAG- $3^{\mathrm{O}}$ and 809R (Jungblut et al. 2005): $5^{\mathrm{O}-G C T T C G G-C A C G}$ GCTCGGGTCGATA-3 ${ }^{\mathrm{O}}$, for cyanobacteria. In both primer sets, the forward primer was labeled with the fluorescent dye 6-FAM (6-carboxyfluorescein) at the $5^{\mathrm{O}}$ end. PCRs were carried out in triplicate $50 \mathrm{ll}$ volumes to minimize reaction bias. Each PCR contained 19 PCR buffer, $200 \mathrm{lM}$ of each dNTP, $0.5 \mathrm{lM}$ of each primer, $0.2 \mathrm{U}$ of DreamTaq polymerase (Fermentas, USA) and $10 \mathrm{ng}$ of template. Thermal cycling conditions for bacterial PCR were a 4-min denaturation step at $94{ }^{\circ} \mathrm{C} ; 30$ cycles at $94{ }^{\circ} \mathrm{C}$ for $30 \mathrm{~s}, 52{ }^{\circ} \mathrm{C}$ for $30 \mathrm{~s}$ and $72{ }^{\circ} \mathrm{C}$ for $105 \mathrm{~s}$; and a final extension step at $72{ }^{\circ} \mathrm{C}$ for $10 \mathrm{~min}$. For cyanobacteria-specific amplifications, PCR conditions were a denaturation step at $94{ }^{\circ} \mathrm{C}$ for a $4 \mathrm{~min}$; 30 cycles at $92{ }^{\circ} \mathrm{C}$ for $20 \mathrm{~s}, 50{ }^{\circ} \mathrm{C}$ for $30 \mathrm{~s}$ and $72{ }^{\circ} \mathrm{C}$ for $1 \mathrm{~min}$; and a final extension step at $72{ }^{\circ} \mathrm{C}$ for $7 \mathrm{~min}$. After amplification, the triplicate PCRs were pooled and purified with an Illustra GFX ${ }^{\mathrm{TM}}$ PCR DNA and Gel Band Purification kit (GE Healthcare, UK), digested separately with HaeIII and MspI (Fermentas, USA) and purified again before the electrophoretic separation using an ABI 3130XL DNA sequencer (Applied Biosystems, USA). Terminal restriction fragments (T-RFs) generated by Peak Scanner software v1.o (Applied Biosystems) were filtered and binned by the method developed by Abdo et al. (2006).

\section{Statistical analysis}

Analysis of variance followed by two sample $t$ tests was used to determine if there were significant differences in operational taxonomic unit (OTU) numbers between sample group (i.e. hypolith vs. soil and fog-dominated vs. rainfall-dominated) at a $95 \%$ confidence interval. 


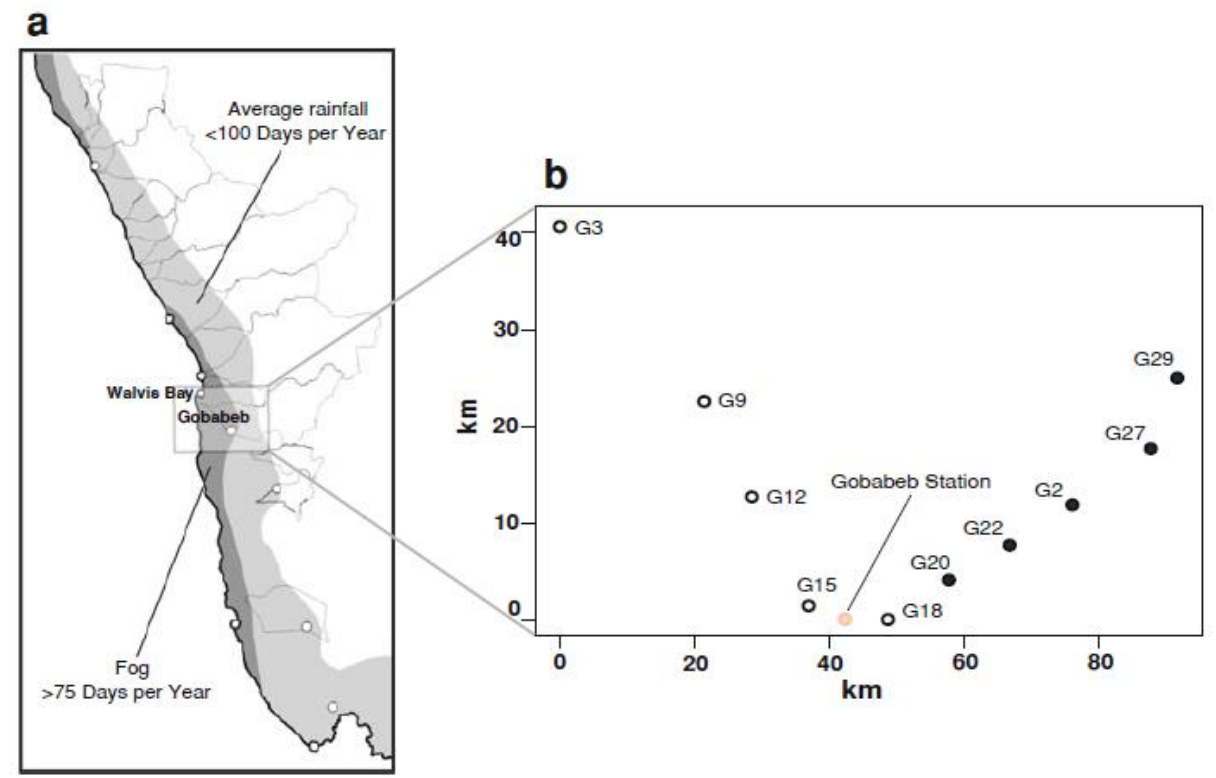

Sample-dissimilarity matrices were generated using the Bray-Curtis coefficient on Hellinger-transformed data (Legendre and Gallagher 2001). Community structure was analyzed using non-metric multidimensional scaling (nMDS). Since nMDS ordination uses an iterative algorithm, an important component of a nMDS plot is a measure of the goodness of fit of the final plot (i.e. stress value). A stress value greater than 0.2 indicates that the plot is close to random, stress less than 0.2 indicates a useful two-dimensional picture, and less than 0.1 corresponds to an ideal ordination (Clarke 1993).

Between-group variation was tested by pairwise analysis of similarity (ANOSIM). Withingroup variation (scatter in the nMDS ordination plots) was compared by dispersion analysis; i.e. by evaluating the differences between sample type and the group centroid (Anderson et al. 2006). Physicochemical data, except $\mathrm{pH}$, were $\log _{10}$-transformed. Climate regime (fog-dominated vs. rainfall-dominated) was included in the models as a dummy (qualitative) variable. Spatial variables were derived from longitude-latitude coordinates using the principal coordinates of neighbor matrices (PCNM) procedure (Griffith and Peres-Neto 2006). Separated forward selection of the environmental and spatial variables was done to find the set of parameters that could best explain the variation in community composition (Ramette 2007). We also used redundancy analysis (RDA) variation partitioning (Peres-Neto et al. 2006) to determine how much of the variation in microbial community composition could be attributed to environment, $E$, and space, $S$. The different components are total explained variation $[E$ ? $S]$, environmental variation $[E]$, spatial variation $[S]$, environmental variation without a spatial component $[E \mid S]$, and spatial variation without the environmental component $[S \mid E]$. Fraction $[U]$ is the amount of variation that remains unexplained $(1-[E ? S])$. Significance testing was done with 999 Monte Carlo permutations, and all $R^{2}$ values were calculated and adjusted 
as described by Peres-Neto et al. (2006). All statistical analyses were performed using the vegan package for R 2.14.1 (http://www.r-project.org/).

Non-random co-occurrence patterns were tested with the checkerboard score ( $C$ score) under a null model preserving site and species frequencies (Stone and Roberts 1990) and using EcoSim software (Gotelli and Entsminger 2009) with the default settings. We calculated a standardized effect size (SES) for each matrix that measures the statistical deviation from random co-occurrence. It is calculated as the number of standard deviations that the observed score is above or below the mean co-occurrence index for the simulated communities $\left[\mathrm{SES}=\left(I_{\mathrm{Obs}}-I_{\mathrm{Sim}}\right) / S_{\mathrm{Sim}}\right]$. Where $I_{\mathrm{Obs}}$ is the $C$ score of the observed incidence matrix, $I_{\mathrm{Sim}}$ is the mean of 5,000 $C$ scores generated from the simulated null model matrices, and $S_{\text {Sim }}$ is the standard deviation of 5,000 simulated communities (Horner-Devine et al. 2007). If the resulting $C$ score is significantly larger than the $C$ score produced by the null distribution, then species co-occur less often than expected by chance (i.e. there is segregation of taxa). If the $C$ score is significantly less than the $C$ score for the null distribution, then more species co-occur than expected by chance (i.e. there is more aggregation among taxa).

\section{Results and discussion}

T-RFLP and statistical analyses were carried out with HaeIII- and MspI-digested samples, independently. As similar results were obtained with both enzymes, only the results from HaeIII digestions are presented here. It must be noted that because hypolithic communities are supported on essentially inert substrates (Pointing et al. 2009), we assume identical chemical parameters in hypoliths and adjacent soil samples for explaining variation in hypolithic community composition (Table 1).

\begin{tabular}{|c|c|c|c|c|c|c|c|c|c|c|}
\hline Sample & G3 & G9 & G12 & G15 & G18 & $\mathrm{G} 20$ & G22 & G2 & $\mathrm{G} 27$ & G29 \\
\hline \multirow[t]{2}{*}{ Coordinates } & $14^{\circ} 40.142^{\prime} \mathrm{E}$ & $14^{\circ} 52.704^{\prime} \mathrm{E}$ & $14^{\circ} 56.781^{\prime} \mathrm{E}$ & $15^{\circ} 01.813^{\prime} \mathrm{E}$ & $15^{\circ} 08.759^{\prime} \mathrm{E}$ & $15^{\circ} 14.028^{\prime} \mathrm{E}$ & $15^{\circ} 19.198^{\prime} \mathrm{E}$ & $15^{\circ} 24.744^{\prime} \mathrm{E}$ & $15^{\circ} 31.773^{\prime} \mathrm{E}$ & $15^{\circ} 34.088^{\prime} \mathrm{E}$ \\
\hline & $23^{\circ} 10.458^{\prime} \mathrm{S}$ & $23^{\circ} 20.502^{\prime} \mathrm{S}$ & $23^{\circ} 25.951^{\prime} \mathrm{S}$ & $23^{\circ} 32.031^{\prime} \mathrm{S}$ & $23^{\circ} 32.699^{\prime} \mathrm{S}$ & $23^{\circ} 30.720^{\prime} \mathrm{S}$ & $23^{\circ} 28.900^{\prime} \mathrm{S}$ & $23^{\circ} 26.436^{\prime} \mathrm{S}$ & $23^{\circ} 23.355^{\prime} \mathrm{S}$ & $23^{\circ} 19.548^{\prime} \mathrm{S}$ \\
\hline Moisture & 4.85 & 6.83 & 5.53 & 3.12 & 3.63 & 4.65 & 5.12 & 5.55 & 3.40 & 5.73 \\
\hline $\mathrm{pH}$ & 8.33 & 8.25 & 8.38 & 7.96 & 8.05 & 8.48 & 8.02 & 8.20 & 8.03 & 7.93 \\
\hline $\mathrm{Na}^{+}$ & 469.98 & 712.80 & 1199.00 & 445.78 & 121.83 & 1382.98 & 53.46 & 314.60 & 41.80 & 20.17 \\
\hline $\mathrm{K}^{+}$ & 166.25 & 405.33 & 218.50 & 201.40 & 197.13 & 549.10 & 168.34 & 116.85 & 222.30 & 109.57 \\
\hline $\mathrm{Ca}^{2+}$ & 14719.50 & 12003.33 & 14926.00 & 2042.50 & 3290.50 & 8386.00 & 2858.40 & 13713.00 & 3990.00 & 3446.67 \\
\hline $\mathrm{Mg}^{2+}$ & 198.60 & 134.80 & 189.60 & 64.80 & 63.30 & 191.40 & 85.68 & 110.40 & 106.80 & 77.60 \\
\hline $\mathrm{C}$ & 0.13 & 0.19 & 0.25 & 0.19 & 0.22 & 0.19 & 0.15 & 0.17 & 0.22 & 0.32 \\
\hline $\mathrm{N}$ & 0.03 & 0.04 & 0.05 & 0.04 & 0.03 & 0.04 & 0.03 & 0.03 & 0.04 & 0.05 \\
\hline
\end{tabular}

For each sample, values are presented as means of five measurements. Moisture content is expressed as percentage wt/wt; $\mathrm{pH}$ is expressed as pH units; total carbon, and total nitrogen are expressed in $\mathrm{g} / 100 \mathrm{~g}$ dry mass. Elemental analysis is expressed as $\mathrm{mg} / \mathrm{kg}$ dry mass

\section{Community patterns}

A total of 245 bacterial T-RFLP-derived OTUs were found among all samples (Figs. 2, 3), of which 75 were unique to the hypoliths and 55 unique to the soils. Cyanobacterial OTUs (78) were detected consistently in all hypolithic samples but in only three of the soil samples. Repeated DNA extractions and T-RFLP PCRs indicated that this result was

\section{http://repository.uwc.ac.za}


reproducible. As a result, only cyanobacteria from hypoliths were considered for further analysis (Figs. 2, 3). Rainfall-dominated hypolithic communities showed relatively higher numbers of unique OTU ( 70 for bacteria and 30 for cyanobacteria) than fog-dominated communities (35 for bacteria and 18 for cyanobacteria) (Kruskal-Wallis test, $P$ [0.05). In contrast, soil bacterial communities exhibited similar OTU numbers irrespective of the climate (41 for fog- and 35 for rainfall-dominated samples, respectively). T-RFLP analysis of soil and hypolithic 16S rRNA gene amplicons showed significant differences in community structure (Fig. 4). When bacterial community patterns were visualized by nMDS, hypoliths exhibited clearly distinct bacterial signatures compared with the surrounding soil (Fig. 4a). Moreover, soil bacterial fingerprints differed more from each other (i.e. showed higher dispersion) than the hypolithic bacteria, though no statistically significant differences were found (Kruskal-Wallis test, $P$ [0.05). This result was greatly influenced by hypolith sample G2 (Fig. 4a, top circle) that presented a very different bacterial community and also the lowest cyanobacterial OTU numbers (Fig. 3). However, by excluding this outlier, a significant difference in sample dispersion was observed (post hoc Wilcoxon-Mann-Whitney test, $P \backslash 0.05$ ). These observations support two major conclusions. First, it is suggested that habitat filtering caused by the unique but more homogenous sub-lithic environmental conditions increases bacterial species similarity within hypolithic communities. The most likely explanation for this is that the overlying rock reduces evaporation and increases water availability (Cockell and Stokes 2004), thus creating an environment suitable for species with higher sensitivity to desiccation (Wood et al. 2008). High relative humidity ( $\mathrm{RH})$ values are consistently recorded in hypolithic zones (Cowan et al. 2010; Khan et al. 2011; unpublished results). Since hypolithic communities were physically dominated by cyanobacterial biomass, these results agree with the concept that autotrophs have lower b-diversity than heterotrophs (Soininen et al. 2007). Second, the differences in microbial community composition between the hypolithic and open soil habitats suggest that hypolithic communities represent reservoirs of microbial diversity for both general bacteria and cyanobacteria in the Namib Desert.

Separation by habitat type (hypoliths vs. open soil; Fig. 4a) was also confirmed by statistically significant ANOSIM results $(R=0.69, P=0.001)$ while no differences were observed between sample sites (fog-dominated/rainfall-dominated) (ANOSIM Global $R=$ o.133, $P[0.05)$. 
Fig. 2 Venn diagrams showing the distribution of T-RFLP fragments (OTU). Hypoliths vs. soils and fog-dominated vs. rainfall-dominated samples (soil bacteria, hypolithic bacteria and hypolithic cyanobacteria)

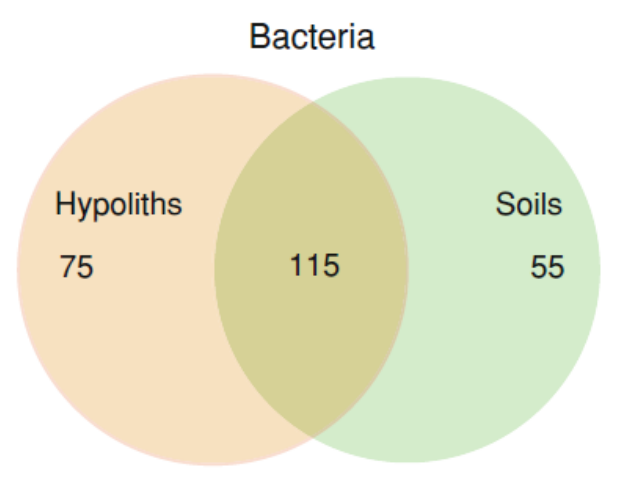

Hypolithic bacteria

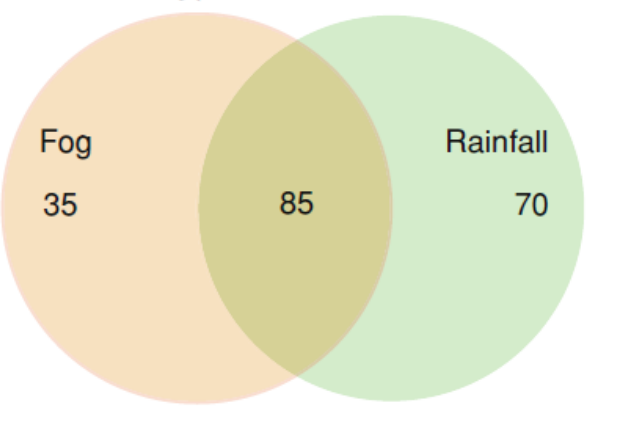

Soil bacteria

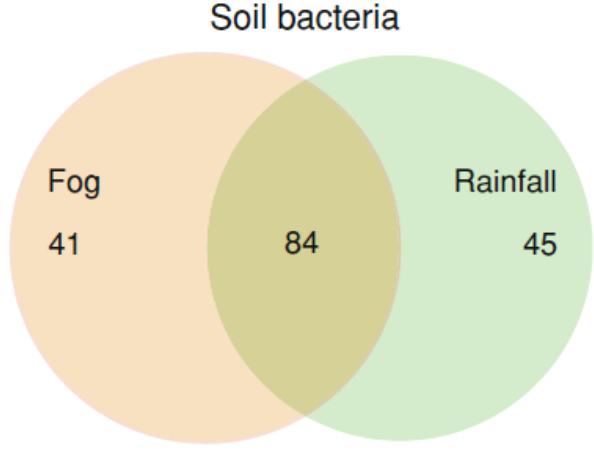

Hypolithic cyanobacteria

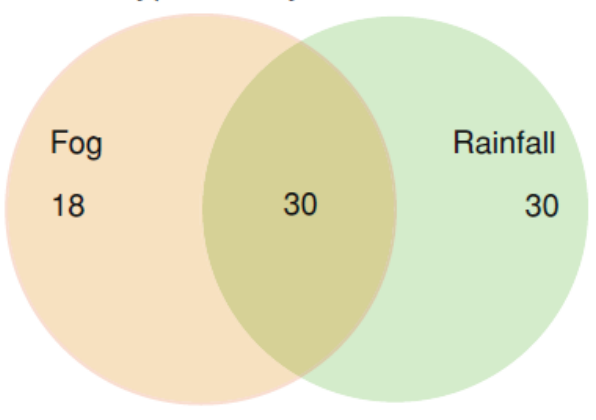

A clear separation in microbial community composition between hypoliths and the surrounding soil has been observed previously (Warren-Rhodes et al. 2006; Pointing et al. 2007, 2009; Tracy et al. 2010; Khan et al. 2011), supporting the concept that the development of hypolithic communities is, at least in part, independent of the bacterial composition in the surrounding soil. When hypolithic and open soil diversity patterns were considered separately, the dominant water regime (fog vs. rainfall) did not influence soil bacterial community patterns (Fig. 4b) (ANOSIM, Global $R=0.02, P[0.05$ ). However, hypolithic bacterial community structures differed significantly between climate regimes (Fig. 4c) (ANOSIM, Global $R=0.244, P=0.02$ ). An even more pronounced influence of climate was observed in the nMDS patterns derived from cyano-bacterial T-RFLPs (Fig. 4d) (ANOSIM, Global $R=0.728, P=0.006$ ).

\section{Effects of the environment and space}

As both habitat type (hypoliths vs. open soil) and climate regime (fog-dominated vs. rainfall-dominated) impacted microbial community structure, we performed canonical RDA to assess the effect of environmental and geographic variables (as PCNM eigenvalues). Water regime (for both the general bacteria and cyanobacterial hypolithic communities) and sodium (for hypolithic cyanobacteria and soil bacteria) were the only two independent environmental variables (Mantel $r=0.021, P=0.343$ ) found to play a role in the variation observed. Furthermore, as the content of $\mathrm{Na}$ in the soil increased, bacterial richness decreased (Pearsons' $r=-0.75, P=0.012$ ). 
In desert ecosystems, even modest levels of soluble salts are thought to be an important determinant of microbial diversity and richness, because water activity, which determines biological water availability, is reduced in the presence of soluble salts (Cowan 2009).

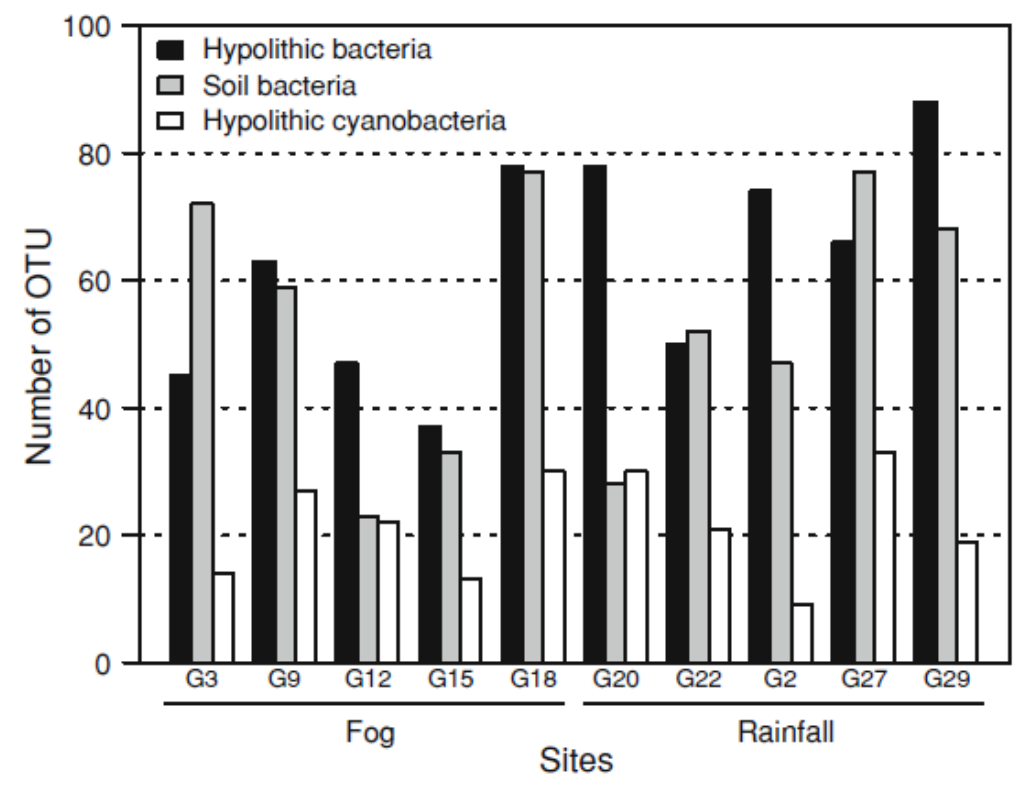

Fig. 3 Number of T-RFLP fragments per sample (fog-dominated vs. rainfall-dominated in hypolithic bacteria, soil bacteria and hypolithic cyanobacteria)

Fig. 4 nMDS ordination plots of T-RFLP profiles for open soil and hypolithic microbial communities. a Hypolithic and soil bacteria, b soil bacteria, c hypolithic bacteria, d hypolithic cyanobacteria. Fogdominated (empty symbols) vs. rainfall-dominated (filled symbols) samples. Gray lines depict groups supported by significant ANOSIM analysis $(P<0.05)$ (see main text). The proximity between samples in the plot corresponds to highcommunity similarity. The quality of the ordination is indicated by a low-stress value

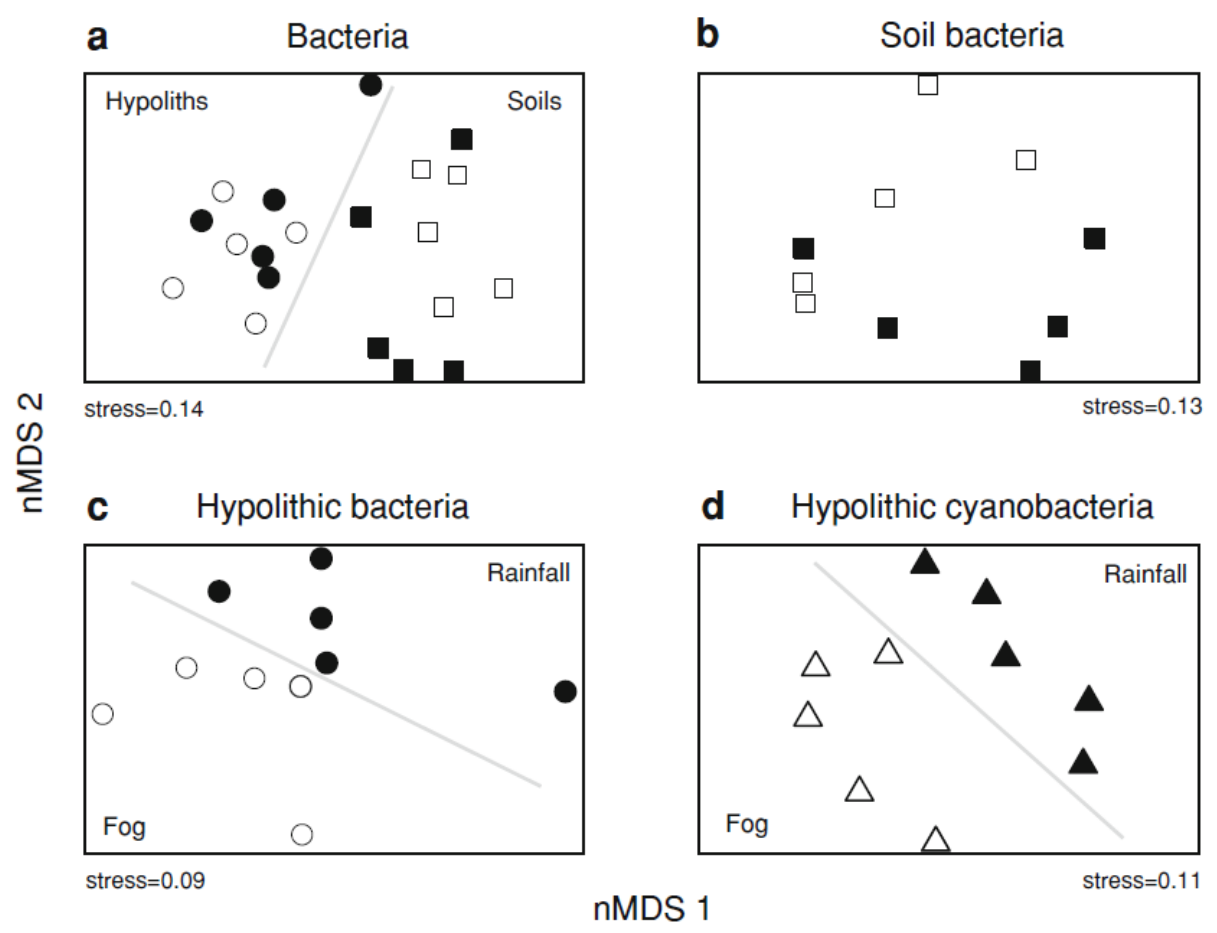


Moreover, moisture together with temperature and photosynthetically active radiation (PAR) are essential parameters that limit the growth and photosynthetic activity of hypolithic cyanobacteria (Schlesinger et al. 2003; Warren-Rhodes et al. 2006, 2007; Tracy et al. 2010). Both available liquid water, derived from rainfall (Warren-Rhodes et al. 2006; Pointing et al. 2007) or fog (Azua-Bustos et al. 2011), and salinity (Thomas 2005; Pointing et al. 2009) have been found to be key determinants of hypolithic communities. Thus, it follows that water regime and sodium content may be essential factors in regulating the extent of microbial community composition in the Namib Desert.

After canonical RDA variation partitioning, the contribution of environment $(E)$ and space $(S)$ to the explained variation in microbial community composition was as follows. For open soil bacterial communities, the environment fraction $(E=[E \mid S ? E \backslash S])$ contributed $13 \%(P=0.025)$, of which $5 \%$ was not spatially structured $([E \mid S])(P[0.05)$. For hypolithic bacteria, no significant contribution was found for any computed factor. For hypolithic cyanobacteria, the environment alone $([E \mid S])$ contributed $14 \%(P=0.008)$ and the confounded effect $([E \backslash S]) 18 \%$ (not testable), giving a total explained variation of $32 \%$ $(P=$ o.01). However, caution is required when interpreting these results since the proportion of variation attributed to the environment depends not only on the strength of environmental control, but also on the specific spatial configuration of the environmental variables and the degree of dispersal limitations (Smith and Lundholm 2010). Moreover, it is important to note that after variation partitioning, 87, 97 and $68 \%$ of the variation (for soil bacteria, hypolithic bacteria and hypolithic cyanobacteria, respectively) remained unexplained. This level of unexplained variation is not uncommon in ecological studies, since variations in species abundance data are often very high (Cottenie 2005; Dumbrell et al. 2010), and different groups of organisms may respond differently to the same environmental factors (Drakare and Liess 2010). The high proportion of unaccounted variation may be attributed to interspecies interaction (e.g. cooperation or competition), environmental factors that were not recorded (e.g. temperature, $\mathrm{RH}$ or dew), stochastic processes (e.g. variation in species population growth rates) or any combination of these.

\section{Null model analysis}

Stochasticity has been predicted to be the main driver of population dynamics under neutral theory (Hubbell 2001). When stochastic processes play a major role, random patterns in species co-occurrence dominate microbial community structure (Bell 2005). By contrast, if environmental factors and species interaction are the principal acting forces, shifts in key environmental variables such as water availability, salinity and $\mathrm{pH}$ may be responsible for the spatial structures found in species assemblages (Fierer and Jackson 2006; Lozupone and Knight 2007; Pointing et al. 2007).

To test whether stochasticity may be important in shaping the structure of microbial communities, we performed null model analysis (Gotelli 2000). We found that soil and hypolithic microbial communities were significantly segregated (i.e., species co-occurred less frequently than randomly predicted) (Fig. 5). Segregation patterns have been originally

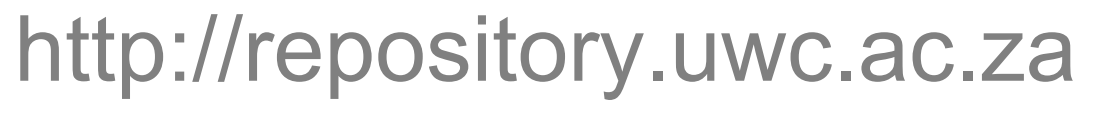


attributed to species interactions (especially competition) or environmental filtering, but the same patterns can also be generated by limited dispersal and historical or evolutionary processes that prevent species from co-occurring in the absence of species interactions (Horner-Devine et al. 2007; Ulrich and Gotelli 2007). Our result is in agreement with a meta-analysis where most of the microbial assemblages showed segregation and very few displayed evidences for aggregation (Horner-Devine et al. 2007) and, together with variation partitioning analysis, suggests that deterministic processes are important for community assembly in the Namib Desert. In addition, although neutral processes may result in nonrandom co-occurrence patterns (Bell 2005), deterministic processes have been shown to predominate in harsh environment and lower productivity systems, whereas stochastic processes predominate in more benign habitats and higher productivity systems (Chase 2007, 2010). There is an increasing perception of the importance of cooperative and competitive interactions between and within bacterial communities (Freilich et al. 2011). Hypolithic cyanobacteria are well-known producers of exopolysaccharide (Pointing et al. 2007), a major component of the extracellular matrix that protects biofilms from harsh environmental factors and may aid in water uptake and retention (Hall-Stoodley et al. 2004).

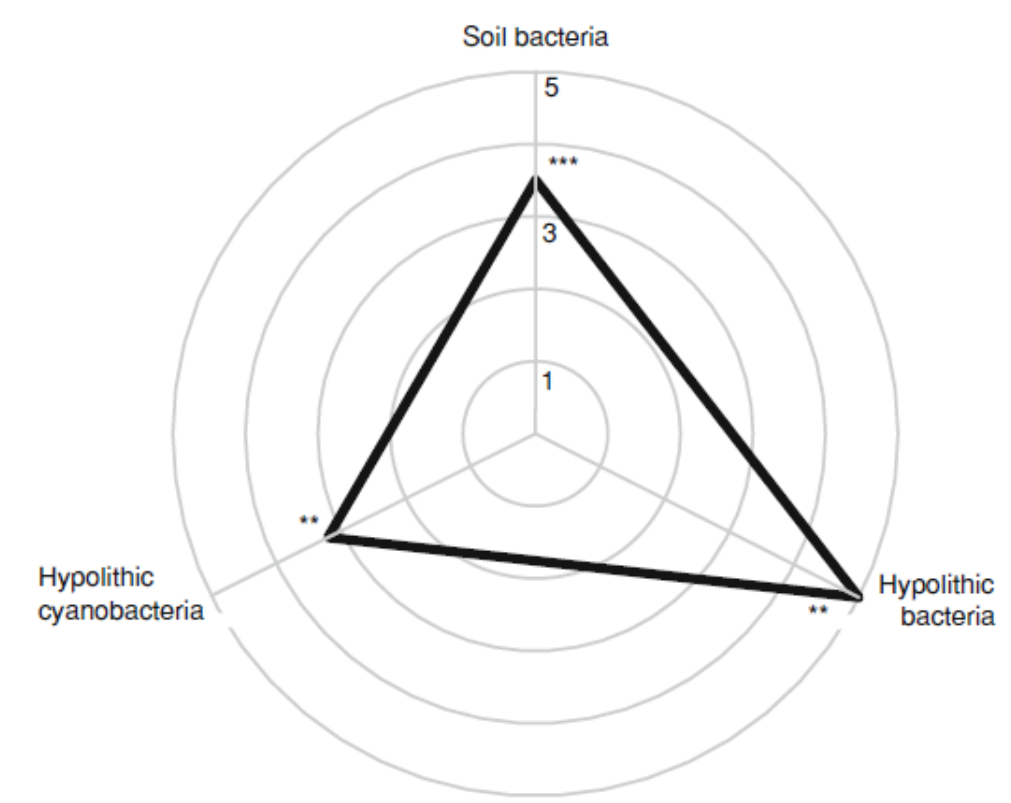

Fig. 5 Radial plot showing the standardized effect size for the $\mathrm{C}$-scores of the different communities. Positive effect size indicates that taxa are more segregated than expected under the null model. Significance levels: $* * * P<0.001, * * P<0.01, * P<0.05$

While EPS secretion may sometimes reflect cooperation among biofilm-dwelling bacteria, evidence suggests that EPS can also mediate competition in biofilms (reviewed in Nadell et al. 2009). Therefore, we agree with Caruso et al. (2011) and believe that inter-specific interactions may contribute to explain differences in the assembly of desert microbial communities. 
Using null models, in contradiction to Caruso et al. (2011), we did not find stochastic signatures to be important in structuring microbial communities; although they used samples from geographically distant deserts, whereas in our study we used a single "local" community. However, given the amount of variability that remains unexplained, it is not unlikely that stochastic processes also play a role in the assembly of bacteria and cyanobacterial communities. Taken together, our results and those from Caruso et al. (2011) are consistent with the concept that drivers shaping the structure of microbial communities depend on the spatial scale (Prosser et al. 2007; Martiny et al. 2011).

A potentially important limitation of our methodology is that DNA fragments with different sequences give rise to similar T-RF sizes. Moreover, in contrast to results obtained through application of clone libraries or next-generation sequencing low abundant taxa are not detected with our method. However, the main aim of our research was not to obtain a full coverage of the diversity in the samples, but rather to monitor variations in the structure of microbial communities that arise from targeting the most abundant taxa in the context of a well-defined water availability gradient determined by fog and rainfall. If we assume the likely hypothesis that states that the dominant microorganisms in a sample are those that play the most important functional role under normal conditions, fingerprinting methods can reveal ecological patterns that help define microbial community structures. Indeed, in a recent study, both 454 pyrosequencing and T-RFLP analysis generated comparable patterns of community composition (Besemer et al. 2012).

In summary, our findings suggest that, on a local scale, deterministic (environmental constraints and interspecies interactions) and, to a lesser extent, stochastic processes are determinants of microbial community' distribution in the Namib Desert. Such processes are critical in a context of global change, and may result in a rapid extinction of these communities if habitat parameters shift at a rapid pace (Thuiller et al. 2005).

\section{Acknowledgments}

The authors gratefully acknowledge F.D. Eckardt for providing Fig. 1a, and the National Research Foundation (South Africa) for support of this research. 


\section{References}

Abdo Z, Schuette UME, Bent SJ, Williams CJ, Forney LJ, Joyce P (2006) Statistical methods for characterizing diversity of microbial communities by analysis of terminal restriction fragment length polymorphisms of $16 \mathrm{~S}$ rRNA genes. Environ Microbiol 8:929-938

Anderson MJ, Ellingsen KE, McArdle BH (2006) Multivariate dispersion as a measure of beta diversity. Ecol Lett 9:683-693

Azua-Bustos A, Gonzalez-Silva C, Mancilla RA, Salas L, Gomez-Silva B, McKay CP, Vicuna R (2011) Hypolithic cyanobacteria supported mainly by fog in the coastal range of the Atacama Desert. Microb Ecol 61:568-581

Bahl J, Lau MCY, Smith GJD, Vijaykrishna D, Cary SC, Lacap DC, Lee CK, Papke RT, Warren-Rhodes KA, Wong FKY, McKay CP, Pointing SB (2011) Ancient origins determine global biogeography of hot and cold desert cyanobacteria. Nat Commun 2:163

Bell G (2005) The co-distribution of species in relation to the neutral theory of community ecology. Ecology 86:1757-1770

Besemer K, Peter H, Logue JB, Langenheder S, Lindstrom ES, Tranvik LJ, Battin TJ (2012) Unraveling assembly of stream biofilm communities. ISME J 6:1459-1468

Bü del B, Darienko T, Deutschewitz K, Dojani S, Friedl T, Mohr K, Salisch M, Reisser W, Weber B (2009) Southern African biological soil crusts are ubiquitous and highly diverse in drylands, being restricted by rainfall frequency. Microb Ecol 57:229-247

Caruso T, Chan Y, Lacap DC, Lau MCY, McKay CP, Pointing SB (2011) Stochastic and deterministic processes interact in the assembly of desert microbial communities on a global scale. ISME J 5:1406-1413

Cary SC, McDonald IR, Barrett JE, Cowan DA (2010) On the rocks: the microbiology of Antarctic Dry Valley soils. Nat Rev Microbiol 8:129-138

Chan Y, Lacap DC, Lau MC, Ha KY, Warren-Rhodes KA, Cockell CS, Cowan DA, McKay CP, Pointing SB (2012) Hypolithic microbial communities: between a rock and a hard place. Environ Microbiol 14:2272-2282

Chase JM (2007) Drought mediates the importance of stochastic community assembly. Proc Natl Acad Sci USA 104:17430-17434

Chase JM (2010) Stochastic community assembly causes higher biodiversity in more productive environments. Science 328: 1388-1391

Clarke KR (1993) Non-parametric multivariate analyses of changes in community structure. Aust J Ecol 18:117-143

Cockell CS, Stokes MD (2004) Widespread colonization by polar hypoliths. Nature 431:414

Cottenie K (2005) Integrating environmental and spatial processes in ecological community dynamics. Ecol Lett 8:1175-1182

Cowan DA (2009) Cryptic microbial communities in Antarctic deserts. Proc Natl Acad Sci USA 106:19749-19750

Cowan DA, Khan N, Pointing SB, Cary SC (2010) Diverse hypolithic refuge communities in the McMurdo Dry Valleys. Antarct Sci 22:714-720 
Cowan DA, Sohm JA, Makhalanyane TP, Capone DG, Green TGA, Cary SC, Tuffin IM (2011) Hypolithic communities: important nitrogen sources in Antarctic desert soils. Environ Microbiol Rep 3:581-586

De la Torre JR, Goebel BM, Friedmann EI, Pace NR (2003) Microbial diversity of cryptoendolithic communities from the McMurdo Dry Valleys, Antarctica. Appl Environ Microbiol 69:3858-3867

Drakare S, Liess A (2010) Local factors control the community composition of cyanobacteria in lakes while heterotrophic bacteria follow a neutral model. Freshw Biol 55:2447-2457

Dumbrell AJ, Nelson M, Helgason T, Dytham C, Fitter AH (2010) Relative roles of niche and neutral processes in structuring a soil microbial community. ISME J 4:337-345

Eckardt FD, Soderberg K, Coop LJ, Muller AA, Vickery KJ, Grandin RD Jack C, Kapalanga TS, Henschel $J$ (2012) The nature of moisture at Gobabeb, in the central Namib Desert. J Arid Environ. doi:10.1016/j.jaridenv.2012.01.011

Fierer N, Jackson RB (2006) The diversity and biogeography of soil bacterial communities. Proc Natl Acad Sci USA 103:626-631

Freilich S, Zarecki R, Eilam O, Segal ES, Henry CS, Kupiec M, Gophna U, Sharan R, Ruppin E (2011) Competitive and cooperative metabolic interactions in bacterial communities. Nature Commun 2:589

Gotelli NJ (2000) Null model analysis of species co-occurrence patterns. Ecology 81:26062621

Gotelli NJ, Entsminger GL (2009) EcoSim: Null models software for ecology. Version 7 (Acquired Intelligence Inc. and Kesey-Bear. Jericho, VT 05465. http://garyentsminger.com/ecosim.htm. 2009)

Griffith DA, Peres-Neto PR (2006) Spatial modeling in ecology: the flexibility of eigenfunction spatial analyses. Ecology 87:2603-2613

Hall-Stoodley L, Costerton JW, Stoodley P (2004) Bacterial biofilms: from the natural environment to infectious diseases. Nat Rev Microbiol 2:95-108

Hansen MC, Tolker-Nielsen T, Givskov M, Molin S (1998) Biased 16S rDNA PCR amplification caused by interference from DNA flanking the template region. FEMS Microbiol Ecol 26:141-149 Henschel JR, Seely MK (2008) Ecophysiology of atmospheric moisture in the Namib Desert. Atmos Res 87:362-368

Horner-Devine MC, Silver JM, Leibold MA et al (2007) A comparison of taxon cooccurrence patterns for macro- and microorganisms. Ecology 88:1345-1353

Hubbell SP (2001) The unified neutral theory of biodiversity and biogeography. Princeton University Press, Princeton, p 448

Jungblut AD, Hawes I, Mountfort D, Hitzfeld B, Dietrich DR, Burns BP, Neilan BA (2005) Diversity within cyanobacterial mat communities in variable salinity meltwater ponds of McMurdo Ice Shelf, Antarctica. Environ Microbiol 7:519-529

Khan N, Tuffin M, Stafford W, Cary C, Lacap DC, Pointing SB, Cowan D (2011) Hypolithic microbial communities of quartz rocks from Miers Valley, McMurdo Dry Valleys, Antarctica. Polar Biol 34:1657-1668 
Legendre P, Gallagher ED (2001) Ecologically meaningful transformations for ordination of species data. Oecologia 129:271-280 Lozupone CA, Knight R (2007) Global patterns in bacterial diversity. Proc Natl Acad Sci USA 104:11436-11440

Martiny JBH, Eisen JA, Penn K, Allison SD, Horner-Devine MC (2011) Drivers of bacterial beta-diversity depend on spatial scale. Proc Natl Acad Sci USA 108:78507854

Nadell CD, Xavier JB, Foster KR (2009) The sociobiology of biofilms. FEMS Microbiol Rev 33:206-224

Ofiteru ID, Lunn M, Curtis TP, Wells GF, Criddle CS, Francis CA, Sloan WT (2010) Combined niche and neutral effects in a microbial wastewater treatment community. Proc Natl Acad Sci USA 107:15345-15350

Peres-Neto PR, Legendre P, Dray S, Borcard D (2006) Variation partitioning of species data matrices: estimation and comparison of fractions. Ecology 87:2614-2625

Pointing SB, Belnap (2012) Microbial colonization and controls in dryland systems. Nat Rev Microbiol 10:551-562

Pointing SB, Warren-Rhodes KA, Lacap DC, Rhodes KL, McKay CP (2007) Hypolithic community shifts occur as a result of liquid water availability along environmental gradients in China's hot and cold hyperarid deserts. Environ Microbiol 9:414-424

Pointing SB, Chan Y, Lacap DC, Lau MCY, Jurgens JA, Farrell RL (2009) Highly specialized microbial diversity in hyper-arid polar desert. Proc Natl Acad Sci USA 106:1996419969

Prestel E, Salamitou S, Dubow MS (2008) An examination of the bacteriophages and bacteria of the Namib desert. J Microbiol 46:364-372

Prosser JI, Bohannan BJM, Curtis TP, Ellis RJ, Firestone MK, Freckleton RP, Green JL, Green LE, Killham K, Lennon JJ, Osborn AM, Solan M, van der Gast CJ, Young JPW (2007) Essay-the role of ecological theory in microbial ecology. Nat Rev Microbiol 5:384-392

Ramette A (2007) Multivariate analyses in microbial ecology. FEMS Microbiol Ecol 62:142160

Reysenbach A, Pace N (1995) Reliable amplification of hyperthermophilic archaeal 16S rRNA genes by the polymerase chain reaction. In: Robb FT, Place AR (eds) Archaea: a laboratory manual-thermophiles. Cold Spring Harbor Laboratory, NY

Schlesinger WH, Pippen JS, Wallenstein MD, Hofmockel KS, Klepeis DM, Mahall BE (2003) Community composition and photosynthesis by photoautotrophs under quartz pebbles, southern Mojave Desert. Ecology 84:3222-3231

Seager R, Ting M, Held I, Kushnir Y, Lu J, Vecchi G, Huang H-P, Harnik N, Leetmaa A, Lau N-C, Li C, Velez J, Naik N (2007) Model projections of an imminent transition to a more arid climate in southwestern North America. Science 316:11811184

Smith TW, Lundholm JT (2010) Variation partitioning as a tool to distinguish between niche and neutral processes. Ecography 33:648-655

Soininen J, Lennon JJ, Hillebrand H (2007) A multivariate analysis of beta diversity across organisms and environments. Ecology 88:2830-2838 
SSSA (1996) Methods of soil analysis, Part 3. Soil Science Society of America, Madison, pp $19-48$

Stone L, Roberts A (1990) The checkerboard score and species distributions. Oecologia 85:74-79

Thomas DN (2005) Photosynthetic microbes in freezing deserts. Trends Microbiol $13: 87-88$

Thuiller W, Lavorel S, Araujo MB, Sykes MT, Prentice IC (2005) Climate change threats to plant diversity in Europe. Proc Natl Acad Sci USA 102:8245-8250

Tracy CR, Streten-Joyce C, Dalton R, Nussear KE, Gibb KS, Christian KA (2010) Microclimate and limits to photosynthesis in a diverse community of hypolithic cyanobacteria in northern Australia. Environ Microbiol 12:592-607

Ulrich W, Gotelli NJ (2007) Disentangling community patterns of nestedness and species co-occurrence. Oikos 116:2053-2061

Walker JJ, Pace NR (2007) Endolithic microbial ecosystems. Annu Rev Microbiol 61:331347

Warren-Rhodes KA, Rhodes KL, Pointing SB, Ewing SA, Lacap DC, Gomez-Silva B, Amundson R, Friedmann EI, McKay CP (2006) Hypolithic cyanobacteria, dry limit of photosynthesis, and microbial ecology in the hyperarid Atacama Desert. Microb Ecol 52:389-398

Warren-Rhodes KA, Rhodes KL, Boyle LN, Pointing SB, Chen Y, Liu S, Zhuo P, McKay CP (2007) Cyanobacterial ecology across environmental gradients and spatial scales in China's hot and cold deserts. FEMS Microbiol Ecol 61:470-482

Wong FKY, Lacap DC, Lau MCY, Aitchison JC, Cowan DA, Pointing SB (2010) Hypolithic microbial community of quartz pavement in the high-altitude tundra of Central Tibet. Microb Ecol 60:730-739

Wood SA, Rueckert A, Cowan DA, Cary SC (2008) Sources of edaphic cyanobacterial diversity in the Dry Valleys of Eastern Antarctica. ISME J 2:308-320 